Doi: $10.31578 /$ jebs.v5i1.191

\title{
The Problem of Teaching of English Pronominal Pronouns in Genderless Society as Applied Linguistic Domain
}

\author{
Mariam Akopian*
}

\begin{abstract}
The paper demonstrates one of the most recent problems in research of grammatical and natural genders in language. The targets of the article are to research gender representations in English from the perspectives of speakers in genderless society and the ways EFL professionals identify the existence of gender-related problems of teaching and learning of English pronominal usage in EFL settings. Literature review discusses how the field of language and gender is becoming re-conceptualized under the influence of theory of language of signs in society construction. The purpose of this paper is to explore how the generic pronoun and he/man approach have been used to perpetuate negative attitudes towards women, exclude them or relegate them from stereotypical roles. The objectives of this paper are to identify the use of gender-insensitive English language use and to suggest ways of making the gender-exclusive language a gender-inclusive one. In order to figure out the awareness and convention of generic pronouns among Georgian speakers of English, a questionnaire was conducted and distributed among EFL professionals working at higher educational institutions in Tbilisi, Georgia.
\end{abstract}

According to the research findings, genderless languages are sexist to a specific degree and representatives of genderless languages might apply biased forms of discourse.

Key words: Generic terms, gender-inclusive, gender-exclusive, sexism, EFL teaching, he/man approach, gender bias, EFL classroom

\section{Introduction}

Gender-related issues of language have been observed and studied by many linguists, mentioning that men and women speak in different ways as well as that men and women are spoken of differently, often stating that language is unfair towards females.

This paper aims to come up with the essential findings concerning the phenomena related to as gender representation in genderless languages, specifically in EFL classroom. With the understanding of the concept of genderless languages (such as Georgian), we deeply assume that languages which do not have a gender system for personal and possessive pronouns, nouns and adjectives, may still demonstrate the gender messages through noun practices. The research problem is defined by the issue that, with the respect to the he/man approach and false generics in English (application of generic he generates gender-exclusivity: such examples are viewed and analyzed as not referring to females), the paper is intended to research and analyze whether and how the application of generic he and he/man approach takes place in English as a foreign/second language for speakers of genderless languages, specifically, Georgian. With the respect of validity of the current research question, the paper will be

\footnotetext{
* MA, International Black Sea University, Georgia

Corresponding Email: makopiani@ibsu.edu.ge
} 
analyzed as a part within the scope of gender encoding in the target language from the perspectives of EFL educators, which will enrich and provide a broader academic context for future linguistic research. This particular piece of research will employ a qualitative research approach, where the individuals' responses and a brief overview of literature review of language and gender studies will extend the concepts of the issue in question.

\section{Literature review}

\subsection{A brief overview of language and gender in educational settings}

Language is considered to be a tool of communication and a means of knowledge of the world around us. Through language understanding and its use, people shape their realization of a society, community, knowledge, norms and values of a community people live in. Education is perhaps the best established domain of applied linguistics. Series of research papers on language and gender has certainly influenced educational debates, decision-making policies and pedagogic practices during the last few decades. With respect to amending the observed gender inequalities in educational world during the 1980s, there was a mass of publications (Hardman, 1993; Tannen, 1993) like guidelines, teaching materials, policy statements designed to publish. Among them, there were many publications (Bodine, 1975; O'Grady, 1997; Sunderland, 2000) focused on language use, both written and spoken. One of the commonly spread issues there might be that of masculinity and femininity which are frequently constructed as discrete and oppositional frameworks of one and the same category. There seems to have been too easy an assumption that boys behave in one way, and girls in another; and that boys and girls alike behave in a consistent manner. Discussions of the question in point - sexist language or sexist biases in educational texts broadly viewed sexism as inherent property of texts. In a similar way, sexist language has been demonstrated in a simplistic and deterministic way as developing language users either as feminine or masculine.

Educational materials play a significant role in transmission of gender domains. Due to feminist movements, many textbooks for children are being examined by researchers, educationists and critics with a belief that children are acute learners of gender roles and that they absorb such gender ideas more promptly and intensely than adults (Otlowski, 2003). Moreover, it has also been established through some researches that the books children read play an important role in developing their gender conceptions (Allan, 1993, 74). Consequently, it is vital to eliminate gender-biased ideas from the textbooks with the purpose of accomplishing gender equity in education. The gender-based analysis of textbooks is now a common practice in different parts of the world wherever there is a concern about gender equality in education sector. Spencer (1986), for example, mentions that people apply only two sexes: male and female. Wardhaugh (2006) adds that gender is a social construct, but which is heavily grounded in sex, involving the whole spectrum of genetic, psychological, social, and cultural differences between males and females. Consequently, the way men and women are viewed may vary from one place to another.

One more classic practice of sexism in language is done through pronoun reference. The sexism in English is also noticed when generic terms are applied in the contexts referring to males, to stand for all human beings in general. The pronoun system uses he, his, and him both in the literal masculine sense and in the generic sense to imply a person of either sex. When such terms are used generically, misinterpretation can take place, and females are unwittingly eliminated from consideration.

There is no pronoun in the English language to refer to a person with unknown pronoun, otherwise called a gender-neutral pronoun. The interest of a linguist here is the context of the use of these pronouns, which make women to become invisible in language. It refers to women's derogation and sorting them on a secondary position. All the way through the historical 
development of a language, the pronoun he/him gradually narrowed in meaning to become a word that refers to adult male human beings. However, it is still in the language today, and it is still often used to refer to males and females.

One more example of inequality in the language use might be noticed in cases where a woman's title is not mentioned, but a man's is highlighted, or where a woman is called only by her first name, while a man is addressed by his title, rank, or first name and surname. The practices mentioned above might create an image that women are treated with less respect or serious consideration compared to man. When men are mentioned as $M r$, he is viewed as a valuable creature, whether he is married or not, while for a female, the distinction between Miss and Mrs has long been essential. However, with the introduction of Ms, a woman is now free not to reveal her marital status. Sexist language practice is also obvious in sorting women referring to their age. Common examples of the issue in question are Miss and Ma'am where Miss refers to a younger woman, while Ma'am to older lady.

\subsection{Gender-exclusive and gender-inclusive language practices}

Language is considered gender-exclusive when particular expressions (support unfair or untrue attitudes to a particular sex, usually women. This type of a language expresses stereotypical attitudes generally towards women and rarely towards men. Therefore, proponents of gender-inclusive language view the use of generic he/man approach as demeaning to woman. The socalled gendered terms such as policeman, salesman, firemen and watchman are generically used, hence exposing sexism in language practices. But even words that seem gender-neutral like doctor, engineer, lawyer and many others are often used as if they apply to one gender - masculine (Cameron, 1985). Their pronoun reference is more often he stating that these high-status jobs are designed for men, nonetheless when a doctor is a female, she is marked as a woman doctor (Thomas \& Wareng, 1999, p.72) which make her viewed as subordinate to male doctors as well as male patients (Romaine, 2004, p.111); consequently, her position in relation to men is inferior (Spencer, 1986, p.194). Similar examples where women are addressed as chairmen of boards or he generically referring to both men and women also abound. It appeared as if the use of gender-neutral forms has not been fully accepted and readers have to be carefully directed that if a woman occupies the position of a chair, the reference is chairperson; otherwise, it is chairman. Gender-exclusive forms maintain status quo, and Romaine (1994) remarks that language is made by men and for men, to represent their points of view and perspectives (p. 105). Overspreading generic he/man and genderspecific pronouns like he are manifestations of linguistic sexism.

Gender-inclusive language is defined as a language that explicitly includes both females and males and that this language diminishes the gender differences. Such a language also gives gender-neutral, gender-fair, non-sexist and gender-free phrases that can be used instead of gender-inclusive practices. However, it is important to mention that if the sex of the antecedent is known to be either male or female then the use of the corresponding pronoun will not be considered to be sexist. However, when references are made to neutral subjects, then there is need to use gender-neutral language. Seemingly, a lot of effort is being expended in transforming sexist attitudes through the use of politically-correct expressions. In some of the books, examples of gender-specific language abound in words like manpower, mankind, salesman, man among others and the pronoun reference used is he. One of the culprits is history books in an example like: The first man lived in caves. Man here is intended to mean both man and woman; similarly, he and himself is supposed to refer back to both man and woman. Once attitudes demoting women to second-rate citizenship are implanted in the minds of young people through association in examples in books, it may be an uphill task to reverse the genders that has already been done. Overall, gender is something that is done and developed in social interactions. 


\subsection{Language as one of the strongest mediums to represent gender ideas}

The popular stereotypes concerning men and women's language status gained in stature when they were recognized by or authorized in the so-called academic and scientific literature of the current life. Men marked their superiority in language through their roles in the dictionary-making process, in the writing of normative grammars, and through their contribution to languageplanning events. On the opposite, women (e.g. mothers, teachers at school) were given some authority in language regulation as norm enforcers. As a result, women were to make certain that children learned to use language properly, specifically following the prescribed rules.

Gender is often defined as features of which a society or culture displays as something masculine or feminine. Moreover, gender defines the relationship between biological sex and the norms that are viewed to be masculine or feminine according to the given culture and society in addition to behavior.

Academic literature (Cook, 2003; Davies, 2007; Larsen-Freeman, 2000) differentiates between two gender theories: biological theory and sociological theory. The biological theory refers to sex differences such as sex attributes, whereas the sociological theory is related to features and norms that are assigned to the sexes by culture and society. Gender roles that are once again assigned by culture or community are maintained by gender norms and appropriate behavior that are differentiated by sex. In addition, gender roles might be also displayed through language as either lexical gender or sexist language. This fact might lead to gender discrimination in language and cause biased sides. As a result, gender studies represent an obvious reality of the issue in question between the sexes. Stereotypes are viewed as mental demonstrations of a specific group and its representatives. These mental views are commonly shaped up due to generalized positive or negative connotations of specific group of people that those people are related to. Stereotypes are mostly persuaded through upbringing and social practices. Hence, language is a crucial factor, specifically, when it comes to the formation / maintenance of stereotypes. Stereotyping a person or a thing mainly depends on cultural and societal practices.

All languages can be differentiated between genders to a varying extent. Gender stereotypes in language are commonly gender specific, where agent words are viewed as male, while social wordings are related to females. A number of studies have shown that cultures with gendered languages demonstrate more sexism compared to cultures with natural gender languages. Literature in question has shown that language can have a significant impact on people's assessment, behaviors and decisionmaking processes. Sexism in language might broaden the break between the sexes and, therefore, hinder gender relations and position of men and women in society.

Since the question of language use affecting gender equality has arisen, various ways of avoiding the generic he have come to use: for example, using both pronouns he or she, using a slash s/he, using singular they, pluralizing the antecedent or dropping the pronoun altogether (Eckert \& McConnell-Ginet, 2003: 69). Less frequently used options include alternating between the generic he and she and using only the generic she. There seems to be no consensus regarding the usage of non-sexist generics. For example, some oppose the use of they as a generic pronoun, since it causes syntactic problems with the verb-subject congruence (Wallraff, 2000: 31). However, this suggested problem is prescriptive in its nature and ceases to exist when they is perceived also as a singular pronoun. The he or she constructions are viewed as clumsy or otherwise stylistically not fitting by some (as some of the participants of the survey expressed, for example) and the generic she is often viewed as female-biased. Regarding the different options of avoiding masculine generics in English, Stahlberg (year) gathered results of studies testing the non-sexist alternatives, e.g. they, he or she and some new, gender neutral, pronouns such as $e$ and tey. The findings were that "explicit reference to women ( $s /$ he, she or he) evoke more 'female' associations than singular they" and that, consequently, singular 
they is perceived as most neutral. They also noted that the alternative generics function effectively as well. Thus it would seem that the singular they or a new, gender neutral, singular $3^{\text {rd }}$ person pronoun would best fit the needs of gender-equal language use.

\section{Research Method}

In this particular paper, the quantitative research approach was applied with the purpose of ensuring the research paper with validity and reliability. Based on the responses gained through the application of a questionnaire, the research will make an effort to study, investigate and examine how speakers of genderless languages are biased and tend to apply sexist practices in genderless society, moreover, a commonly spread tendency of he/man approach among EFL educators in Georgia, and the part gender takes in EFL classroom were also studied and analyzed in this research.

\subsection{Research questions and hypothesis}

Based on the brief background information concerning language and gender issues described in this article, the following research questions have been shaped:

1) To what extent do you believe that language learning is nearly inevitably bound to studying gender-related issues?

2) Who are the most sexist users of language in your EFL classroom, male or female students?

The hypothesis is the following:

Despite of the fact that genderless languages do not have a grammatical gender system, speakers of genderless languages are to a certain degree biased and sometimes apply sexist language.

\subsection{Research goal, tool and data collection}

The research goal was to explore how the generic pronoun and he/man approach have been used to perpetuate negative attitudes towards women, exclude them or relegate them from stereotypical roles. With the understanding of the concept of genderless languages, this paper aims to come up with the essential findings concerning the phenomena related to gender representation in genderless languages, specifically in EFL classrooms.

The research tool was the questionnaire that was conducted and was sent via email to 20 English language educators in Georgia. The subjects of the survey were English language educators both in high schools and higher educational institutions in Georgia (the ones having a broad teaching experience in mixed-sex groups in multilingual and multicultural students' audiences). There were six statements in the questionnaire where the EFL educators had to make the choice whether they agree, strongly agree, disagree, or strongly disagree, moreover, the participants responded to the theoretical questions supporting with reviewed returns. The responses were analyzed and presented in the chart in the appendix. Research findings are considered to evidence the validity and reliability of the research hypothesis.

\section{Data collection method}

The EFL educators, interested in this field of study, were invited to act as subjects of the research questionnaire. For this particular piece of research, the purposeful selection method was used, where $20 \mathrm{EFL}$ educators from Georgia interested in the issue volunteered to participate in the study. It is noteworthy to mention that the research provided the participants with confidentiality, where all necessary permissions were obtained. The questions might be best described as being of two types: 1) the subjects 
marked the answers whether they strongly agree, agree, disagree or strongly disagree with the claims connected to language and gender teaching understanding; 2 ) the participants responded to the theoretical questions. The collected findings of the survey were employed to determine the gender bias among the users of genderless languages and identify potential sources of language misinterpretations.

\subsection{Data analysis and results}

Referring to the responses collected from EFL educators regarding the teaching awareness of gender-related peculiarities, the further conclusions should be stated. In reference to that language is necessarily bound up to learning the gender-related peculiarities in EFL classroom, 50\% of the subjects of the survey marked the response as strongly agree and $15 \%$ - agree. So, although more than half of the respondents believe that gender-related issues are important, many enough (35\%) do not think so. Probably, the reason is that Georgian grammar does not have gender category. This is the answer to the first research question.

Concerning the second item to be assessed, which stated that in the educational process one gender is usually honoured more than the opposite, there is an equal number of the subjects who agrees (30\%) and disagrees (30\%) and almost the same number of the respondents who strongly agree (15\%) and strongly disagree (25\%). Therefore, according to Georgian teachers of English, their students do not very much favor the application of one gender (masculine) over the other. Thus, the hypothesis of the research is only to a certain degree supported.

With regard to the third item, which stated that male students use language in a more sexist way than female students, almost a half of the participants strongly agree, whereas there is an almost equal allocation of the replies among the other options. It is important to note that a larger part of the respondents either strongly agrees (45\%) or agrees (20\%) with the issue.

The majority of the respondents realize that EFL educators have to apply gender-neutral forms of language in EFL classroom (like businessperson, police officer, etc.) that will create neutrality and gender stability, which will decrease language discrimination practices in EFL classroom (40\% strongly agree and $50 \%$ agree). It is possible to expect, according to these answers, that the majority of Georgian students of English are taught to use gender in a politically correct way.

According to the participants, the majority of them disagrees (35\%) or strongly disagrees (30\%) with the statement that Georgian speakers of English are gender-biased and tend to apply sexist language, however, many enough (totally $35 \%$ ) think so. Again, the hypothesis of the research is only partially supported. It is possible to say that the absence of grammatical gender category in a language does not completely prevent the use of sexist language.

$75 \%$ of the respondents strongly agree that culture has a great impact on gender-related peculiarities, $15 \%$ agree with the statement, while $10 \%$ disagree with it. Thus, the majority of the respondents understand the importance of culture in gender perception.

On the whole, the participants strongly believe that gender has an important part in EFL educational settings. Furthermore, they view culture as an influential factor in building language learning environment in terms of integrating it to gender-related practices. However, practically every participant mentioned that male language learners are the ones who tend to use biased or sexist wordings through the demonstration of male imaginary forms and interpretations. This claim responds to the first research question that asked who the most sexist language users are - males or females.

In case of linguistic misconception or misinterpretation, EFL educators provide their learners with gender-neutral alternatives: provide semantic clues, apply he/she style, use singular they, or substitute with gender-neutral words, like chairperson, 
mailman, etc. Overall, EFL educators in Georgia, desist from sexist wordings in their educational settings by providing neutral alternatives and avoiding cultural stereotypes that are embrace males and females in Georgian society.

Language and communication have a great power to influence a common ground and reality even though any new change might cause controversy and resistance.

The obtained results just let researchers and teachers think deeper on the stated problem, as the number of participants does not let the researcher to make generalizations. To make generalizations, wider-scale research is necessary.

If the obtained results are compared to international research on the topic, it is possible to see similar results: PrewittFreilino, Caswell and Laakso (2016) study found by comparing 111 countries that those where gendered languages are spoken evidence less gender equality compared to those with other (genderless and gender-fair) grammatical gender systems.

\section{Conclusion}

Considering linguistic change as a significant part of social change, it obviously attains to draw connections between genderrelated linguistic phenomena and gender inequality or discrimination. The studies of language and gender show that the meanings are originated by language, emphasizing to the fact that linguistic features are not explicitly related to individual attributes such a person's sex, hence, there are various gender ideologies that shape up daily interactions and practices, and display them in a sensible manner in social settings. Current paper has given insides of different viewpoints for analyzing the relationship between gender and variation in genderless society, specifically, among Georgian speakers of English. Nevertheless, the attempts of the implementation of non-sexist language patterns are frequently met with negative reactions and hostile attitudes.

\section{References}

Allan, H.T. (1993). Feminism: A concept analysis. Leading Global Nursing Research, 18 (10), 1547-1553.

Bodine, A., 1975. Androcentrism in prescriptive grammar: Singular 'they', sex-indefinite 'he', and 'he or she'. Language in Society, 4 (2), 129-146.

Cameron, D. (1992). Feminism and Linguistic Theory. (1 ${ }^{\text {st }}$ ed.) London: Palgrave Macmillan UK.

Cook, G. (2003). Applied Linguistics. (1 $1^{\text {st }}$ ed.) Hong Kong: Oxford University Press .

Davies, A. (2007). An Introduction to Applied Linguistics. (2 ${ }^{\text {nd }}$ ed.) Northampton: Edinburgh University Press.

Eckert, P. \& McConnell-Ginet, S., 2003. Language and Gender. New York: Cambridge University Press.

Hardman, M. (1993). Gender through the levels. Women and Language, 16 (2), $42-49$.

Larsen-Freeman, D. (2000). Techniques and Principles in Language Teaching. ( $2^{\text {nd }}$ ed.) Oxford: Oxford University Press.

O'Grady, W. (1997). Contemporary Linguistics. $3^{\text {rd }}$ ed. Boston: Omega Publishing Services.

Otlowski, M. (1997). Voluntary Euthanasia and the Common Law. $7^{\text {st }}$ ed. New York: Clarendon Press Oxford. 
Prewitt-Freilino, J.L., Caswell, T.A., \& Laakso, E.K. (2012). The gendering of language: A comparison of gender equality in countries with gendered, natural gender, and genderless languages. Sex Roles, 66, 268-281.

Romaine, S. (1982). Women, Men and Language: A Sociolinguistic Account of Gender Differences in Language. ( ${ }^{\text {rd }}$ ed.) London: Routledge Linguistics Classics.

Spencer, J. (1986). The Rise of the Woman Novelist - From Aphra Behn to Jane Austen. s.l.:Basil Blackwell.

Sunderland, J. (2000). Issues of language and gender in second and foreign language education. Language Teaching, 33(04), 203223.

Tannen, D. (1993). Gender and Conversational Interaction. $2^{\text {nd }}$ ed. New York: Oxford University Press

Linda Thomas, S. W., 2004. Language, Society and Power: An Introduction. London and New York: Routledge.

Wardhaugh, R., 2006. An Introduction to Sociolinguisitcs. 5th ed. Victoria: Blackwell Publishing.

Wardhaugh, R. \& Fuller, J. M. (2015). An Introduction to Sociolinguistics. 7th ed. Oxford: Wiley Blackwell.

\section{Appendix: Questionnaire survey results}

Language-learning is almost inevitably tied to learning of gender-

related issues in an EFL classroom

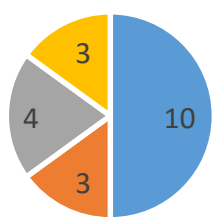

$$
\begin{array}{ll}
\text { - strongly agree } & \text { agree } \\
\text { - disagree } & \text { strongly disagree }
\end{array}
$$

Learning is almost always skewed in such

a way to favor one gender over the other

$$
\begin{array}{ll}
\text { - strongly agree } & \text { " agree } \\
\text { - disagree } & \text { - strongly disagree }
\end{array}
$$


Male students use language in a more sexist way

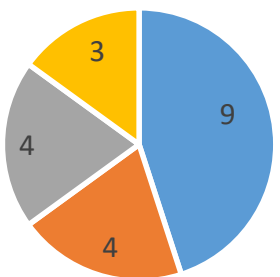

- strongly agree

- agree

- disagree

- strongly disagree

Georgian learners of English are biased and prefer using masculine forms

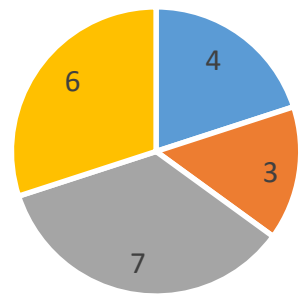

- Strongly Agree - Agree

- Disagree $\quad$ - Strongly Disagree
As an EFL teacher, you have to use gender-neutral forms, e.g. chairperson, police officer, etc.

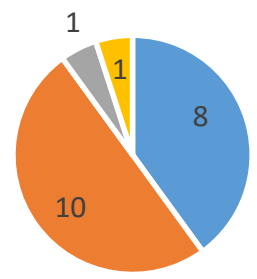

- strongly agree $\quad$ agree

- disagree $\quad$ strongly disagree

\section{Culture affects language learning} concerning gender studies

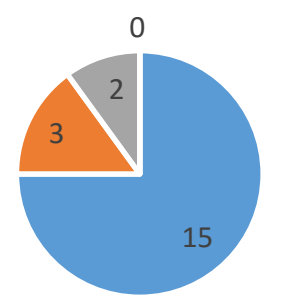

$$
\begin{array}{ll}
\text { - strogly agree } & \text { agree } \\
\text { - disagree } & \text { a strongly disagree }
\end{array}
$$

